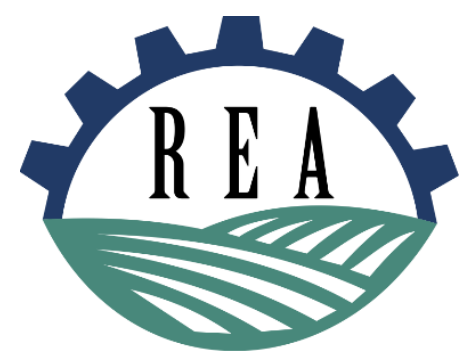

Revista de Economia e Agronegócio - REA

ISSN impresso: 1679-1614

ISSN online: $2526-5539$

Vol. $15 \mid$ N. 3 | 2017

EDITORIAL

\title{
O MUNDO RURAL BRASILEIRO: HISTÓRIA, TENDÊNCIAS ATUAIS E OS DESAFIOS PRINCIPAIS DO “PRÓXIMO PERÍODO”
}

\author{
Zander Navarro* \\ *Empresa Brasileira de Pesquisa Agropecuária (EMBRAPA), \\ Brasília, Distrito Federal, Brasil. \\ E-mail: zander.navarro@embrapa.br
}

Para responder com correção, pelo menos factual, ao proposto no título desse sucinto editorial analítico, é preciso acionar as luzes oferecidas pela interpretação histórica e salientar inicialmente pelo menos dois fatos cruciais. Primeiramente, convém tomar como ponto de partida lógico o esforço de modernização agrícola empreendido durante os governos militares, sobretudo durante o período compreendido entre 1968 e 1981. Não obstante as inúmeras deformações sociais e políticas do ciclo autoritário, naqueles anos, o crescimento da agricultura ativou a formação de uma geração de produtores rurais que, gradualmente, passou a ser movida por uma única categoria econômica - o lucro. Entre eles se encontravam, sobretudo, mas não exclusivamente, produtores sulistas, e a soja foi o carro-chefe do processo de transformação produtiva $\mathrm{e}$ aperfeiçoamento tecnológico do setor. Tais produtores integravam também o grupo de empreendedores que, no meio século seguinte, até os nossos dias, foi crescentemente motivado a ampliar os seus negócios e buscar maior rentabilidade, para isso se tornando francamente receptivo às possibilidades do progresso técnico, enquanto se aventurava em novas fronteiras agrícolas no centro do país.

O segundo aspecto típico das cinco décadas anteriores tem uma dupla face. Como ponto positivo, cabe destacar que, uma vez ultrapassada a grave crise econômica do início da década de 1980, o 
setor agropecuário brasileiro vem quase sempre "salvando" a economia brasileira, especialmente através dos saldos comerciais anuais, não somente positivos, mas também superiores aos saldos dos demais setores econômicos. Simultaneamente, ampliou-se a capilaridade espacial do setor, que, de forma gradual, se espalhou para outras regiões, inicialmente em direção ao Centro-Oeste e, mais recentemente, para o Norte e Nordeste do país. O lado negativo, contudo, é que a sociedade brasileira, no geral, não obstante o papel decisivo da agropecuária, quase sempre ignorou o "mundo rural" e suas peculiaridades, se mostrando desinteressada em relação aos processos econômicos e produtivos em curso nesse longo período de transformações. Durante esses anos, somente em situações especialmente traumáticas, quase sempre em função de conflitos sociais (Eldorado dos Carajás, por exemplo), é que a "sociedade urbana" voltou seus olhos para as regiões rurais.

São aspectos que, em consequência, indicam um primeiro desafio que precisaria ser vencido com alguma urgência. Não obstante o recente lançamento do livro "Economia e organização da agricultura brasileira" (CHADDAD, 2017), conhecemos insuficientemente, seja como sociedade ou, até mesmo, como comunidade de pesquisadores, a nossa própria história rural, inclusive a mais recente. Não temos sequer um livro que descreva com abrangência a trajetória do desenvolvimento agrário do Brasil nesse meio século passado, o que bem demonstra a carência da produção científica sobre "o rural" e seus processos sociais e econômicos. Não fossem tão limitados (e ideologizados, em larga proporção) os nossos esforços acadêmicos e os respectivos resultados da pesquisa, explicaríamos detalhadamente essa trajetória e, provavelmente, identificaríamos diferentes períodos, ou fases, da história rural do Brasil no período contemporâneo. E, quase certamente, delimitaríamos uma fase singularíssima, iniciada na segunda metade da década de 1990. Nessa etapa, não apenas a produtividade total de fatores deu um salto (em 1997), como também, logo depois, se evidenciaram os números relativos à impressionante expansão estimulada pelas compras chinesas de mercadorias, produzindo o chamado "boom de commodities" e a respectiva elevação de preços, o que caracterizou a primeira década desse século.

Havendo alguma concordância acerca das especificidades dessa fase recentíssima, se perceberia, por exemplo, que impressionantes mudanças econômico-financeiras, produtivo-tecnológicas e socioculturais estão em curso atualmente em todas as regiões rurais brasileiras, mudando radicalmente a face agrária do passado, tão enfatizada na literatura convencional, ou através de vozes urbanas que desconhecem o vasto mundo do interior brasileiro. Somente como ilustração, bastaria examinar as mudanças espaciais que vêm alterando profundamente diversas regiões rurais, como o caso de São Paulo, que é hoje um "mar de cana", mas continua sendo o estado 
com maior valor obtido com as exportações agrícolas, pois ainda mantém uma eficiente diversificação produtiva. O Pará, por exemplo, observa uma fase de expansão agrícola e pecuária igualmente impressionante. É possível citar ainda o "arco produtivo", quase inexistente há apenas duas décadas, que compreende o oeste baiano, passando por Goiás e ocupando largas regiões centrais do Mato Grosso: uma vasta área que, lentamente, vai se tornando a mais importante no tocante à produção agrícola moderna. Em síntese, esta, que seria uma "fase distinta" do nosso desenvolvimento agrário, tem apresentado uma sísmica movimentação espacial de profundas transformações, com a emersão de regiões de intenso dinamismo econômico e produtivo. Todavia, são novidades que os brasileiros quase sempre desconhecem e das quais as áreas de pesquisa, por enquanto, ainda mantêm algum distanciamento analítico. Portanto, mesmo como uma hipótese de trabalho inicial e cautelosamente submetida, é preciso um esforço de investigação para analisar a seguinte pergunta (e, sobretudo, as suas implicações): deixamos o Brasil agrário do passado, e, atualmente, a história rural estaria cada vez mais, de modo intenso, conformada estritamente por determinantes econômicos? Se, em alguma medida, a resposta a essa pergunta for afirmativa, sem dúvida mudariam os processos e temas a serem analisados, pois, igualmente, estaria sendo transformada, de forma radical, a face societária das regiões rurais.

Eis o pano de fundo proposto. Aberto o novo roteiro a ser trilhado pela história à frente, nos anos vindouros, quais seriam então alguns dos temas principais a que a ação governamental, a agenda de pesquisa, as organizações dos produtores, os agentes privados e, enfim, todos os atores sociais ligados mais diretamente ao "rural" deveriam prestar atenção? Indicados, com extrema brevidade, alguns fatos do passado, o que é possível apontar como tendências principais e mais relevantes deste período específico em que vivemos?

Na limitação deste espaço, saliento sinteticamente cinco novidades dos anos recentes: (a) a importantíssima reversão de uma faceta típica do passado, em que prevalecia a "oferta abundante de mão de obra" e, à la Lewis, o fator trabalho quase nunca representava um custo de maior significação. Atualmente, em todas as regiões rurais, a escassez de trabalho vem se impondo, o que acarretará uma "onda de mecanização" jamais vista em nossa história rural; (b) o esvaziamento demográfico do campo brasileiro, comprovado por diversos indicadores censitários ou sugeridos pelas sucessivas PNADs, desde o início dos anos 1990; (c) o aprofundamento notável da heterogeneidade estrutural vigente no território rural, de certa forma "condenando" diversas regiões, enquanto outras demonstram vigoroso dinamismo econômico; (d) a crescente integração e condução das regiões rurais a uma lógica econômica específica que conduz o processo de transformação. Ao que parece, existe, de fato, 
um desenvolvimento capitalista, agora instalado como o condutor do setor agropecuário, não apenas no tocante às mentalidades sociais, mas, em especial, no cotidiano da organização da produção; (e) finalmente, a outra novidade, antes esboçada, seria o fim do "passado agrário" e sua dramaturgia social e política, sepultando temas que pareciam eternos, como a reforma agrária, por exemplo. Se esse último assunto se mostrar real e concreto, então, até mesmo a concentração fundiária (e seus termos demonizados, como "latifundiários"), aspecto que calou fundo no imaginário coletivo dos brasileiros, terá uma dimensão estrutural que, certamente, não encontrará mais nenhuma chance de ser modificada no futuro.

Se essas são algumas das características salientes, hoje fincadas nos solos rurais do Brasil, o que nos reservaria o "próximo período", ou o futuro no médio prazo, seja no âmbito da pesquisa e das políticas públicas, ou entre os participantes das cadeias dos distintos ramos produtivos? Sem poder listar e analisar os demais, novamente destaco quatro grandes campos de investigação que devem aflorar como principais nos anos vindouros. Não discutirei os temas da chamada "agenda velha", como os problemas de logística e armazenamento, que vêm sendo discutidos há muitos anos.

Primeiramente, é claríssima e inevitável a tendência à concentração da riqueza no setor, em todas as suas modalidades (não apenas no que tange à concentração fundiária), e à dominação da agricultura de larga escala, que, como agente econômico, já prevalece sobre praticamente toda a agropecuária, direção na qual deve se aprofundar nos anos seguintes. Se for assim, o "lugar social e econômico" dos estabelecimentos rurais de menor porte será ainda mais reduzido e, portanto, o destino dos pequenos produtores deve se tornar um tema relevante. Essa afirmação supõe, por certo, que os temas "agrários" do passado, como a redistribuição fundiária, deverão deixar definitivamente os debates nacionais. São inúmeras as implicações dessa primeira tendência, e cito uma delas meramente para ilustrar: neste novo mundo rural, dominado pela grande empresa agropecuária internacionalizada, qual será, por exemplo, o papel de uma empresa pública de pesquisa agrícola como a Embrapa? Contudo, há temas sociológicos fascinantes decorrentes desse processo aparentemente apenas econômico-financeiro. Como a agropecuária vai se transformando em espetacular máquina de produção de riqueza, há um "transbordamento" mais amplo, produzindo um processo abrangente de mercantilização da vida social e, portanto, diversos processos sociais e culturais novos estão emergindo em muitas regiões rurais.

O segundo grande tema a ser enfatizado é circunscrito geograficamente e diz respeito ao Nordeste rural, mais especificamente, ao semiárido nordestino, que já é a região rural mais pobre, a mais populosa e, também, a mais ameaçada pelas mudanças 
climáticas, pela elevação das temperaturas e pela escassez de recursos hídricos. Haverá a chance de ocorrer alguma revolução tecnológica que garanta a produção agropecuária em meio ao esvaziamento demográfico de seus ambientes rurais? É improvável que haja e, por isso, o Nordeste rural deverá aflorar como um controverso tema de debate nacional nos anos vindouros. Poderá se transformar em um deserto demográfico com bolsões de produção agropecuária, circunscritos a ilhas onde exista alguma disponibilidade de água.

O terceiro tema relevante que precisa ser enfatizado diz respeito ao financiamento geral da produção agropecuária em um país que está na iminência de se tornar o maior produtor de alimentos do mundo. $\mathrm{O}$ diagnóstico, nesse caso, é direto: o Estado vai perdendo capacidade relativa de financiar, como no passado, o custeio da safra, além dos investimentos necessários e, consequentemente, recorre ao capital privado dos bancos, depois dos fornecedores e outros agentes econômicos e, por fim, dos investidores externos. Em decorrência disso, parece ser inevitável um processo de internacionalização da agropecuária brasileira, o que igualmente exigirá também a facilitação da presença do capital externo em todo o sistema agroalimentar, incluindo a propriedade da terra. Em breve, portanto, se observará a discussão política (e não apenas econômica) sobre a presença do capital externo como uma exigência inadiável para garantir as necessidades financeiras da produção.

Finalmente, o quarto tema a ser salientado diz respeito à ação governamental para o setor. O Estado brasileiro e seus segmentos, sobretudo o MAPA e suas vinculadas, têm se mostrado largamente ineficazes em sua compreensão sobre os desenvolvimentos agrário e agrícola recentes no Brasil e, por isso, têm agido quase sempre com a mente no retrovisor, repetindo o rol de políticas do passado, enquanto as realidades da produção (e da vida social rural) têm sido alteradas profundamente. Agiganta-se, assim, a ineficácia da ação governamental, sendo, por isso, esperado que sejam desenvolvidas crescentes formas de contestação social e política diante da inoperância da esfera estatal.

Em síntese conclusiva, nesta quadra histórica, o Brasil observa um contexto de imensa ambiguidade em relação à produção agropecuária e às regiões rurais e suas populações. Há um vibrante processo de produção de riqueza em curso, de crescente complexidade e sofisticação tecnológica, mas denso em contradições de muitas ordens: dos desafios sociais às necessidades financeiras, das fragilidades institucionais às inquietações tecnológicas. Em particular, há uma abissal insuficiência interpretativa, tanto por parte do Estado como também por parte de considerável parcela dos pesquisadores interessados em temas rurais. É preciso que nós, estudiosos desse campo, apliquemos um esforço em pesquisa que

Revista de Economia e Agronegócio - REA | V. 15 | N. 3 | 2017 | pág. 297 
seja muito mais ambicioso, a fim de produzir melhores respostas à longa lista de desafios ocasionados atualmente pelas transformações do mundo rural brasileiro.

\section{Referência}

CHADDAD, F. Economia e organização da agricultura brasileira. São Paulo: Elsevier, 2017. 176 p. 